\title{
NEURAL NETWORK MODEL FOR PREDICTION OF THE PERMEATE FLUX OF MACROMOLECULAR SOLUTIONS WITH GUAR AND XANTHAN GUMS IN CROSSFLOW MICROFILTRATION PROCESSING
}

\author{
E. R. FILLETTI ${ }^{1}$, J. M. SILVA ${ }^{2}$ \\ ${ }^{1}$ Department of Physical Chemistry, Institute of Chemistry, São Paulo State University - UNESP, \\ Araraquara - SP, Brazil \\ ${ }^{2}$ Institute of Science and Technology, Federal University of Alfenas - UNIFAL, \\ Poços de Caldas - MG, Brazil \\ E-mail address: erica@iq.unesp.br

\begin{abstract}
RESUMO - The purpose of this research work is to develop an artificial neural network model that predicts the permeate flux of macromolecular solutions with guar and xanthan gums in ceramic membrane of nominal pore size of $0.2 \mu \mathrm{m}$ and $0.4 \mu \mathrm{m}$ to two different temperatures. The neural network has been trained through a selected set of experimental data already published. The experimental data were obtained for the concentration in turbulent flow. Few experimental series were considered to construct a database applied to neural model parameters that could be adjusted. The input variables of neural model were temperature, nominal pore size and microfiltration time. The results show that the neural model can be trained in a reasonable computational time and it is able to predict real values of the permeate flux.
\end{abstract}

\section{INTRODUCTION}

Cross flow membrane filtration technology has been used widely in industry globally. During filtration processes, fouling is the main problem causing loss of productivity. Indeed, it reduces equipment efficiency with permeate flux decline, increases production cost by repetitive cleaning and can induce contamination problems due to the growth of microorganisms at the membrane surface. Therefore, extensive studies of the characterization of fouling have been several researchers. Most of the studies have focused on the evolution of permeate flux. Evaluating parameters related with the transport phenomena, often request complex mathematical equations with adjustable parameters that are difficult to determine experimentally and the analytical solution cannot be obtained. In this context, artificial neural networks (ANNs) have attracted attention as new approach for determining complex relationships between input and output variables on analysis of experimental data.

ANNs have several advantages that make them attractive tools: they can be trained to learn from examples; are easily updated and generalized; possess a large degree of freedom and accurate prediction at high speed (Nafey, 2009, Valle and Araujo, 2011, Niemi, et al., 1995). ANNs possess 
the ability to identify a relationship from given patterns and this makes it possible to solve large-scale complex problems. As a consequence, several researchers have devoted to study the application of neural networks models in crossflow filtration process. Razavi, et al., 2004 applied neural networks for the dynamic simulation of permeate flux and total hydraulic resistance. The methodology was used to the case of milk concentration by crossflow ultrafiltration as a function of physicochemical conditions ( $\mathrm{pH}$ and fat per cent). The results were satisfactory with average error less than $1.06 \%$. Curcio, et al., 2006 presented ANN methodology for the control of permeate flux decay, on the basis of the experimental results collected, during ultrafiltration of BSA solutions. Liu, et al., 2009 used ANN models to predict the performance of microfiltration systems for water treatment. Five input variables were used in order to construct a database for development neural model to predict and/or simulate membrane fouling behavior. Guadix, et al., 2010 develop an ANN that predicts the time evolution of the milk permeate flux through a ceramic membrane submitted to operational cycles of filtration and cleaning with different degrees of aggressivity. The results show satisfactory with an error of 10\%. Authors as Niemi et al. 1995, Shetty et al. 2003, Curcio et al. 2005, Chellam (2005), Shahoo and Ray (2006), Silva and Flauzino (2008) and Hilal et al. 2008 also worked with the applicability of ANNs to describe membrane processes.

In order to obtain a tool to estimate parameters of crossflow filtration process, the aim of this research is to investigate the possibility of using a neural network to predict the permeate flux. In particular, ANN was developed to estimate the permeate flux during the microfiltration of macromolecular solutions with guar and xanthan gums in turbulent flow with ceramic membrane of nominal pore size of $0.2 \mu \mathrm{m}$ and $0.4 \mu \mathrm{m}$ to two different temperatures, $25^{\circ} \mathrm{C}$ and $40^{\circ} \mathrm{C}$. The database for development neural model was obtained by experimental data of the literature (Queiroz and Fontes, 2008). The results obtained by the artificial neural network have shown to be satisfactory, with average error of $6 \%$.

\section{EXPERIMENTAL DATA}

As previously mentioned, the experimental method and data set used in this research were described by Queiroz and Fontes (2008). In order of elucidate, in this section, a brief summary of the method is reported. Figure 1 shows a schematic drawing of the experimental equipment used to analyze the concentration process by microfiltration. The experimental system was manufactured by Netzsch do Brazil Ltda, with one ceramic tube module $1000 \mathrm{~mm}$ (4, Figure 1) long, $7 \mathrm{~mm}$ diameter each a surface area of $0.022 \mathrm{~m}^{2}$. The solution in the feed tank (1, Figure 1) was made to circulate using a positive-displacement pump (2, Figure 1) and the transmembrane pressure was maintained constant by a frequency in versor. The retention flux was returned to the feed tank, whereas the permeate outflow was volumetrically measured (5, Figure 1) as a function of time (Fontes, et al., 2005). The commercial ceramics membranes used in this research has nominal pore size of $0.2 \mu \mathrm{m}$ and $0.4 \mu \mathrm{m}$. The transmembrane pressure was measured with a manometer before the module at 300 $\mathrm{kPa}$. The concentrations used were: $750 \mathrm{ppm}$ of xanthan gum with $250 \mathrm{ppm}$ of guar gum. 


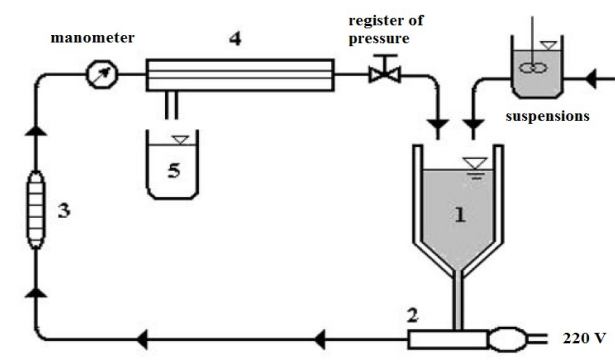

Figure 1. Schematic drawing of the experimental apparatus: (1) jacketed fluid container; (2) pump; (3) flowmeter; (4) covering module with membrane; (5) permeate outflow.

\section{NEURAL NETWORK ALGORITHM IMPLEMENTATION}

In this work it is used a feed forward network, i.e., the input of a specific layer is formed only by the values of the preceding layer. The architecture of such a network is composed of an input layer, a certain number of hidden layers and an output layer in forward connections, as shown in Figure 2. Each neuron in the input layer represents a just single input parameter. These values are directly transmitted to the subsequent neurons of the hidden layers. The neurons of the last layer represent the ANN's outputs.

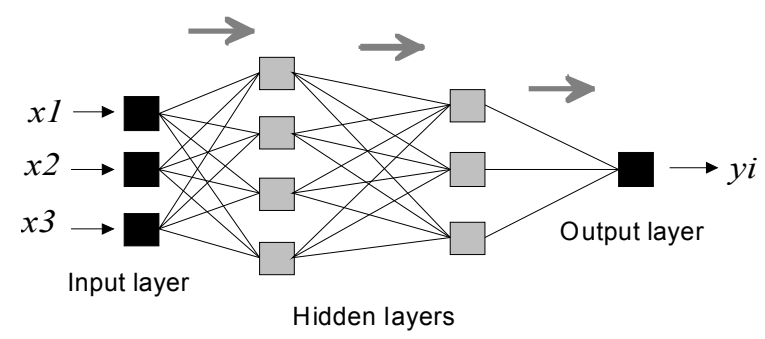

Figure 2: Representation of a feed forward neural network.

The output $y_{i, j}$ of neuron $i$ in a layer $j$ is calculated as

$$
\begin{aligned}
& y_{i, j}=f\left(v_{i, j}\right) \\
& v_{i, j}=\sum_{k=1}^{L} w_{k, i, j-1} y_{k, j-1}+b_{i, j}
\end{aligned}
$$

where $f$ is the activation function, $L$ is the number of connections to the previous layer, $w_{k, i, j-1}$ corresponds to the weights of each connection and $b_{i, j}$ is the bias. The activation functions used in the 
neural network, in this work, were the tangent sigmoid in the hidden layers and a linear function in the output layer, expressed respectively as

$$
\begin{aligned}
& f\left(v_{i, j}\right)=\frac{2}{\left(1+\exp \left(-2 v_{i, j}\right)\right)}-1 \\
& f\left(v_{i, j}\right)=v_{i, j}
\end{aligned}
$$

The training process in the ANNs involves presenting a set of examples (input patterns) with known outputs (target output) (Jenkins, 1997). The system adjusts the weights $w_{k, i, j}$ of the internal connections to minimize errors between the network output and target output. The knowledge is represented and stored by the weights of the connections between the neurons.

Back propagation is probably the most used training algorithm and it is particularly well adapted to feed-forward architecture of the multi-layer network. It is based on the iterative application of a discrete gradient descent algorithm, designed to compute the connection weights minimizing the total mean-square error between the actual output of the network and the target output. In general, the back propagation algorithm, which is implemented in this work, can be summarized as follows (Hayhin, 1999):

(i) initialize the ANN's parameters $b_{i, j}$ and $w_{k, i, j}$ with random numbers;

(ii) calculate the outputs of all the neurons of layer by layer, starting with the input layer until the output layer using Equations (1) - (4);

(iii) calculate the mean square error by:

$$
M S E=\frac{1}{2} \sum_{i=1}^{N}\left(d_{i}-y_{i}\right)^{2}
$$

where $y_{i}$ is the actual output of the $i$-th output node, $d_{i}$ is the corresponding desired output and $N$ is the number of output nodes;

(iv) calculate the derivatives of the error with respect to $b_{i, j}$ and $w_{k, i, j}$;

(v) update the weights and bias along the negative gradient of the $M S E$ and a specified learning rate $\gamma$

$$
b_{i, j} \leftarrow b_{i, j}-\gamma \frac{\partial(M S E)}{\partial b_{i, j}}
$$




$$
w_{k, i, j} \leftarrow w_{k, i, j}-\gamma \frac{\partial(M S E)}{\partial w_{k, i, j}}
$$

(vi) repeat by going to step 2 , successively modifying $b_{i, j}$ and $w_{k, i, j}$, up to a certain number of epochs to be achieved or until MSE is sufficiently small.

The neural network implemented in this work has three inputs and one output. Various architectures were trained and tested. The neural model that had the best result, obtained by trial and error, has two hidden layers with six and three neurons, respectively.

The training procedure comprehended the acquisition time, temperature and pore size (input patterns) obtained as described in section previous. Thirty-six examples of data were considered to construct a database applied to ANN parameters that could be adjusted. The error of the training was the order of $10^{-4}$, as shown in Figure 3. The neuron of the output layer is responsible for estimating the permeate flux $(J)$.

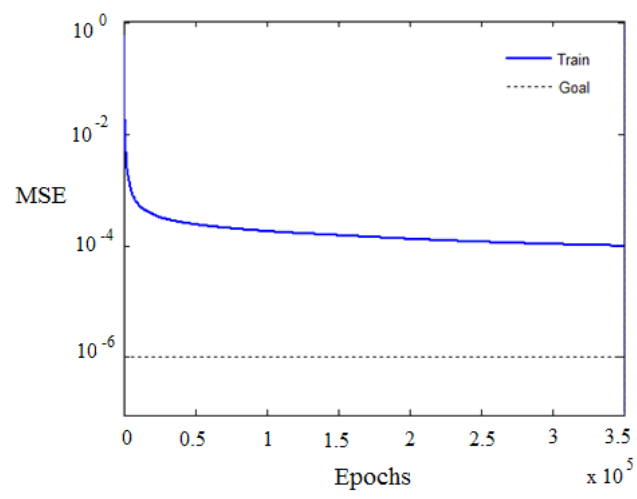

Figure 3: Decrease of the error during the training of the ANN.

To determine the values of the learning rate, the number of epochs as well as the number of neurons in the intermediate layers of the neural networks, an optimization of the parameters of the neural networks was performed by trial and error, in an attempt to diminish the error in a reasonable time. The learning rate used in the neural network was 0.1 and the training time was approximately 2 hours and 350000 epochs were performed during the training. For the generalization, 12 examples different from those used in the training were presented to the neural network. The division of the examples in training and test sets was made randomly and was obtained a good coefficient of correlation among the data.

\section{RESULTS AND DISCUSSION}

To evaluate the generalization capacity of ANN, new experimental data were presented to the neural networks. It is good to emphasize that these data were unknown to the ANN. A good 
correlation among the input and output data could be observed for the test set.

Figures 4 and 5 show comparison of the data obtained experimentally Queiroz and Fontes (2008) with of the results calculated by neural network, concerning the examples contained in the test set, for the average permeate flux of mixture in suspension of guar and xanthan gum as a function of the time. The ANN results presented in this figure showed good agreement with the experimental data with average relative error equal to $0.7 \%$ and $2.6 \%$ in the case of membrane pore size of $0.2 \mu \mathrm{m}$ and temperature of $25^{\circ} \mathrm{C}$ (Fig. $4 \mathrm{a}$ ) and $40^{\circ} \mathrm{C}$ (Fig. 4b), $19 \%$ and $1.2 \%$ in the case of membrane pore size of $0.4 \mu \mathrm{m}$ and temperature of $25^{\circ} \mathrm{C}$ (Fig. 5a) and $40^{\circ} \mathrm{C}$ (Fig. 5b).

(a)

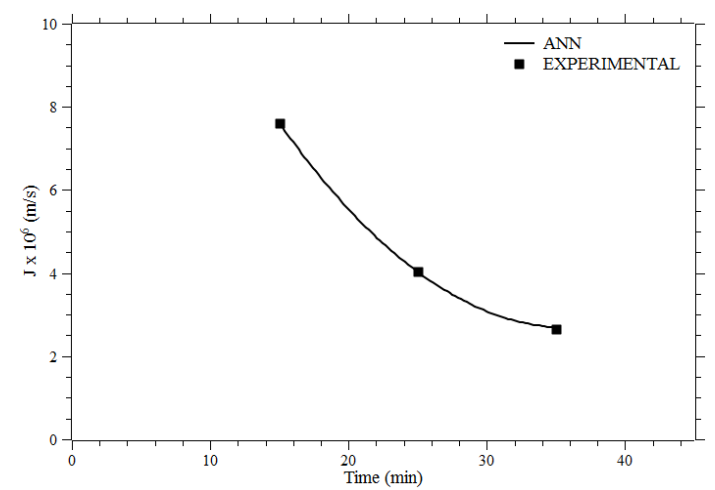

(b)

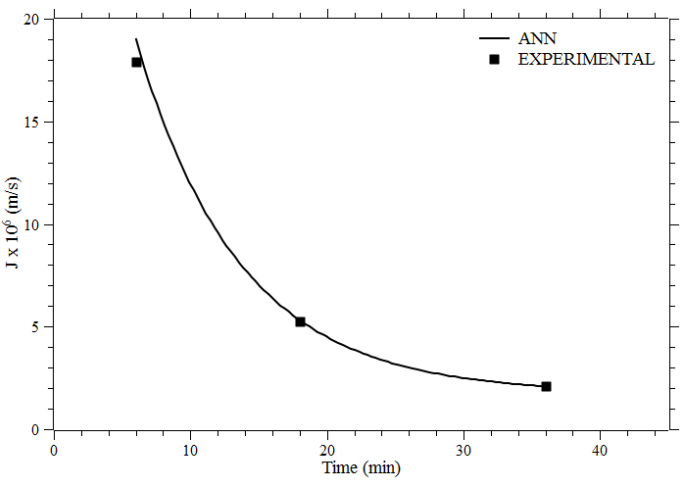

Figure 4: Average permeate flux as function of the time membrane pore size of $0.2 \mu \mathrm{m}:$ (a) temperature equal to $25^{\circ} \mathrm{C}$; (b) temperature equal to $40{ }^{\circ} \mathrm{C}$.

(a)

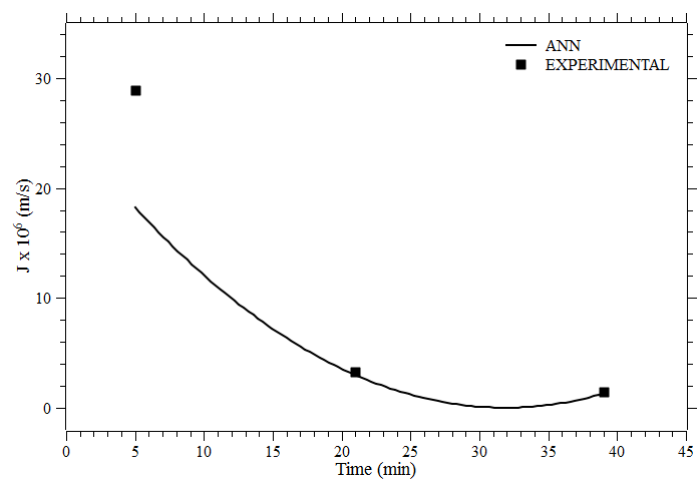

(b)

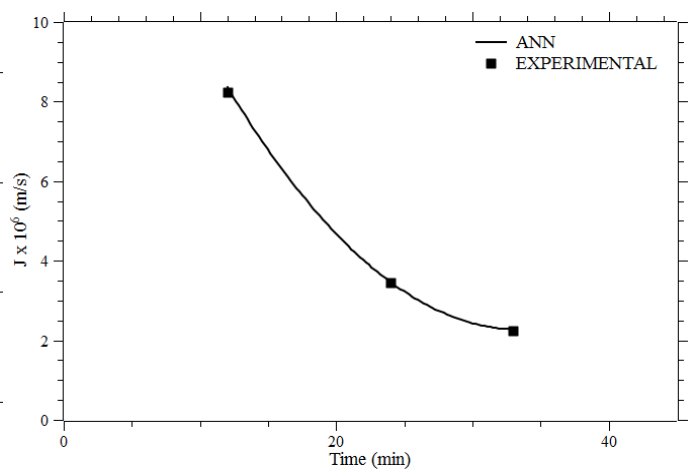

Figure 5: Average permeate flux as function of the time membrane pore size of $0.4 \mu \mathrm{m}$ : (a) temperature equal to $25^{\circ} \mathrm{C}$; (b) temperature equal to $40{ }^{\circ} \mathrm{C}$.

Figure 6 shows the line that best approximates the values obtained by the neural model whose equation is $y=1.27 x-0.93$. As can be observed, the results obtained by ANN for the test examples 
are satisfactory, with a Pearson correlation $R^{2}=0.9$ and an average relative error of $6 \%$ was observed. These results indicate that the training of the proposed neural model has been successfully performed.

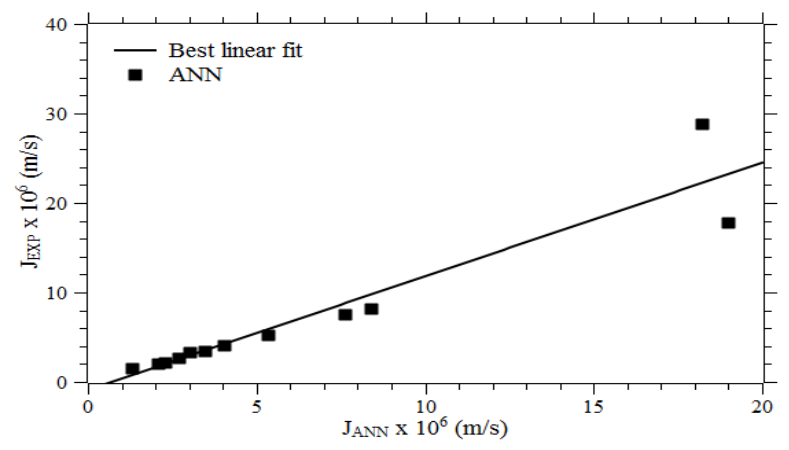

Figure 6: Best linear fit for values of the average permeate flux estimated by the $\operatorname{ANN}\left(J_{A N N}\right)$ and the experimental data $\left(J_{E X P}\right)$ membrane pore size of $0.2 \mu \mathrm{m}$ and $0.4 \mu \mathrm{m}$.

\section{CONCLUSIONS}

Artificial neural model was trained with experimental data in order to determine the average permeate flux in the crossflow membrane microfiltration process. To construct a database, a small number of examples were used, from which the ANN parameters (weights and biases) were adjusted. A model was developed to map the parameters time, temperature and pore size membrane with the aim of estimating the permeate flux. The results of the artificial neural network were satisfactory, as it showed to be capable of estimating the values of the permeate flux of mixtures for examples that were not presented to it in the training, with average error of $6 \%$.

The simplicity and efficiency of the developed neural approach indicates that the proposed methodology can be used as an efficient method to estimate parameters related to the crossflow membrane microfiltration process.

\section{ACKNOWLEDGEMENTS}

The authors would like to acknowledge the financial support of CNPq, FAPEMIG and FAPESP. Special thanks are also due to Dr. Sérgio Rodrigues Fontes (in memorian) for letting us to make use of the set of experimental data.

\section{REFERENCES}

CHELLAM, S. Artificial neural network model for transiente crossflow microfiltration of polydispersed suspensions. J. Membr. Sc., 258, 35-42, 2005.

CURCIO, S., SCILINGO, G., CALABRÒ, V., IORIO, G. Ultrafiltration of BSA in pulsating 


\section{9 a 22 de outubro de 2014 \\ Florianópolis/SC}

conditions: an artificial neural networks approach. J. Membr. Sc., 246, 235-247, 2005.

CURCIO, S., CALABRÒ, V., IORIO, G. Reduction and control of flux decline in cross-flow membrane processes modeled by artificial neural networks. J. Membr. Sc., 286, 125-132, 2006.

GUADIX, A., ZAPATA, J.E., ALMECIJA, M.C., GUADIX, E.M. Predicting the flux decline in milk cross-flow ceramic ultrafiltration by artificial neural networks. Desalination, 250, 1118-1120, 2010.

FONTES, S. R., QUEIROS, V. M. S., LONGO, E., ANTUNES, M. V. Tubular microporous alumina structure for demulsi fying vegetable oil/water emulsions and concentrating macromolecular suspensions. Sep. Purif. Technol., 44, 235-241, 2005.

HAYKIN S. Neural Networks: a comprehensive foundation. 2nd ed. New Jersey: Prentice Hall, 1999.

HILAL, N., OGUNBIYI, O.O., AL-ABRI, M. Neural network modeling for separation of bentonite in tubular ceramic membranes. Desalination, 228, 175-182, 2008.

JENKINS, W.M. An introduction to neural computing for the structural engineer. The Structural Engineering, 75(3), p.38-41, 1997.

LIU, Q.F., KIM, S.H., LEE, S. Prediction of microfiltration membrane fouling using artificial neural networks models. Sep. Purif. Technol, 70, 96-102, 2009.

NAFEY, A. S. Neural network based correlation for critical heat flux in steam-water flows. Int. J. Thermal Sc., 48, 2264-2270, 2009.

NIEMI, H., BULSARI, A., PALOSAARI, S. Simulation of membrane separation by neural networks. J. Membr. Sc., 102, 185-191, 1995.

QUEIROZ, V.M.S., FONTES, S.R. Experimental analysis of structural change and rheological behavior of macromolecular solutions with guar and xanthan gums in crossflow microfiltration processing. Food and Bioprocess Tech., 1, 180-186, 2008.

RAZAVI, M.A., MORTAZAVI, A., MOUSAVI, M. Application of neural networks for crossflow milk ultrafiltration simulation. Int. Dairy J., 14, 69-80, 2004.

SAHOO, G.B., RAY, C. Predicting flux decline in crossflow membranes using artificial neural networks and genetic algorithms. J. Membr. Sc., 283, 147-157, 2006.

SILVA, I.N., FLAUZINO, R.A. An approach based on neural networks for estimation and generalization of crossflow filtration processes. Applied Soft Computing, 8, 590-598, 2008.

SHETTY, G.R., CHELLANM, S. Prediction membrane fouling during municipal drinking drinking water nanofiltration using artificial neural networks. J. Membr. Sc., 217, 69-86, 2003.

VALLE, D. B., ARAUJO, P. B. Utilização de redes neurais artificiais para o ajuste dos parâmetros do controlador POD do dispositivo FACTS IPFC. Proceedings of the 9th Latin-American Congress on Electricity Generatiom and Transmission - CLAGTEE 2011, 2011. 